CLINICAL STUDY

\title{
Gestational thyroid function abnormalities in conditions of mild iodine deficiency: early screening versus continuous monitoring of maternal thyroid status
}

\author{
Mariacarla Moleti ${ }^{1}$, Vincenzo Pio Lo Presti ${ }^{1}$, Filiberto Mattina ${ }^{1}$, Alfredo Mancuso ${ }^{2}$, Antonio De Vivo ${ }^{2}$, \\ Grazia Giorgianni $^{3}$, Beatrice Di Bella ${ }^{1}$, Francesco Trimarchi ${ }^{1}$ and Francesco Vermiglio ${ }^{1}$ \\ ${ }^{1}$ Dipartimento Clinico-Sperimentale di Medicina e Farmacologia- Sezione di Endocrinologia, ${ }^{2}$ Dipartimento di Scienze della Riproduzione, Sezione di \\ Patologia Ostetrica and ${ }^{3}$ Dipartimento di Scienze Biochimiche, Fisiologiche e della Nutrizione- Servizio di Biochimica Clinica, University of Messina, \\ 98125 Messina, Italy \\ (Correspondence should be addressed to F Vermiglio who is now at Cattedra di Endocrinologia, Policlinico Universitario, Via Consolare Valeria, 98125 \\ Messina, Italy; Email: francesco.vermiglio@unime.it)
}

\begin{abstract}
Objective: To longitudinally evaluate the timing of maternal thyroid underfunction occurrence in mildly iodine-deficient (ID) pregnant women, and ultimately assess the benefit of thyroid function testing at early gestation only in identifying maternal thyroid underfunction.

Participants/methods: Serum free-thyroxine and TSH were measured in 220 consecutive women once in early pregnancy (by week 12) and twice per trimester subsequently. Anti-thyroperoxidase and antithyroglobulin were also determined at initial and final observation.

Results: Thyroid autoantibodies were detectable in $8.2 \%$ women. Overall, the prevalence of hypothyroidism over the course of gestation was $11.8 \%(26 / 220)$, with a relative risk of hypothyroidism in antibody-positive women of $5.0\left(\chi^{2} 20.02, P<0.0005\right)$. Nonetheless, almost $70 \%$ hypothyroid women tested negative for thyroid autoantibodies. Fifteen/26 (57.7\%) hypothyroid women were identified at presentation, and the remaining 11 at either early $(6 / 11)$ or late $(5 / 11)$ phases of the 2nd trimester. Isolated hypothyroxinemia was observed in 56/220 (25.4\%) women, mostly from the 2nd trimester onwards.

Conclusions: In mildly ID areas thyroid function testing early in gestation seems to be only partly effective in identifying thyroid underfunction in pregnant women. Indeed, in our series more than $40 \%$ hypothyroid women would not have been diagnosed had we limited our observation to early thyroid function tests alone. Although thyroid autoimmunity carried a 5-fold increased risk of hypothyroidism, iodine deficiency seems to be a major determinant in the occurrence of thyroid underfunction. Adequate iodine supplementation should be strongly recommended to meet the increased hormone demand over gestation.
\end{abstract}

European Journal of Endocrinology 160 611-617

\section{Introduction}

There is a known association between untreated maternal hypothyroidism and increased risk of several adverse outcomes for both mother and foetus at all stages of pregnancy $(1,2)$. Moreover, children born to mothers who experience even mild thyroid insufficiency at early gestational stages may be at risk for neuromotor and cognitive deficits (3-5). In view of the severity of these consequences, and the awareness that they may be successfully prevented by prompt therapeutic intervention, many have recommended that thyroid function screening be routinely performed in pregnant women (6-8). Conversely, other investigators recommend thyroid function evaluation only in symptomatic women or in those with a personal history of thyroid disease (9-12). In the latest guidelines for the management of maternal thyroid dysfunction during pregnancy the authors conclude that recommending universal screening may be premature. Nonetheless, the expert panel does agree that maternal thyroid function testing is advisable in selected groups of women considered to be at high risk for thyroid disease (aggressive targeted case-finding) (13).

Whatever the strategy, i.e. universal screening or case-finding, there is broad agreement on the advisability of performing maternal thyroid function tests as early as possible after conception. Performing the tests at this early stage, however, could pose the risk that any maternal thyroid underfunction occurring later in gestation might not be picked up. In an attempt to assess this risk, we conducted an observational study on a cohort of consecutive pregnant women living in a mildly iodine-deficient (ID) area, whose thyroid function 
had been longitudinally monitored throughout gestation. The main aim of this study was therefore, to evaluate the timing of maternal thyroid failure occurrence in mildly iodine-deficiency and ultimately assess whether or not maternal thyroid function testing performed at an early stage in gestation only is in fact appropriate in detecting maternal thyroid underfunction in pregnant women from mildly ID areas.

\section{Subjects and methods}

\section{Area studied, clinical monitoring programme and participants}

The study was carried out in a presently mildly ID (median urinary iodine excretion (UIE) $99.7 \mu \mathrm{g} / 24 \mathrm{~h}$; goitre in school children 16.3\%) area of North-eastern Sicily that was previously classified as moderatelyseverely or moderately ID (1976-1980 UIE 25.5土 $23.6 \mu \mathrm{g} / 24 \mathrm{~h}$; goitre in school children $65 \%$; $1989-$ 1991 UIE $48.1 \pm 38.2 \mu \mathrm{g} / 24 \mathrm{~h}$; goitre in school children $31.7 \%)(14,15)$. A wide range of neurointellectual disorders have been reported in school children from the area and attributed to various degrees of maternal thyroid insufficiency occurring during gestation $(3,15-17)$. Based on this evidence, we set up a monitoring programme to track maternal thyroid function over the full course of gestation and, later on, a programme of iodine prophylaxis aimed at preventing/correcting any maternal thyroid insufficiency occurring during gestation in order to ultimately avoid neuro-behavioural and intellectual disorders in progeny was offered on a voluntary basis (18).

All pregnant women living in this area were invited to participate in our prevention programme. Women were first sampled not later than week 12 at first trimester and twice more in the second and third trimester (at $\sim 6$ week intervals). Thyroid function testing included serum free-thyroxine $\left(\mathrm{FT}_{4}\right)$ and TSH determinations. In assessing maternal thyroid function, we refer to both serum $\mathrm{FT}_{4}$ and TSH internal trimester-specific reference intervals calculated in a cohort of consecutive longterm iodine-supplemented healthy anti-thyroperoxidase (TPO-Ab) antibody-negative pregnant women (18). At initial and final sampling TPO-Ab and anti-thyroglobulin $(\mathrm{Tg}-\mathrm{Ab})$ antibodies were also determined.

All women found to be subclinically or overtly hypothyroid throughout gestation were given substitutive levo- $\mathrm{T}_{4}\left(\mathrm{~L}-\mathrm{T}_{4}\right)$. Women with mildly isolated hypothyroxinemia ( $\mathrm{IH}$, serum $\mathrm{FT}_{4}$ values below the lower limit of the trimester-specific reference range and TSH concentrations within the trimester-specific reference range), were also given substitutive $\mathrm{L}_{\mathrm{T}} \mathrm{T}_{4}$, in line with the purely experimental design of the study.

To date, 426 pregnant women have been referred to our outpatient clinic. For the purposes of this study, $108 / 426$ women were ineligible because they were receiving $\mathrm{L}_{-} \mathrm{T}_{4}$ replacement or semi-suppressive therapy for post-surgical hypothyroidism or nodular goitre prior to becoming pregnant. A further $98 / 426$ women did not fulfil inclusion criteria either because they were not enrolled at early pregnancy or did not complete the scheduled follow up. The remaining 220 women, who had never been tested for thyroid dysfunction prior to becoming pregnant, made up our sample study. These women were variously iodine-supplemented. Indeed, in addition to the regular use of iodised salt, more than one half of them also received multivitamin compounds specifically prepared for pregnancy and containing iodine (100-150 $\mu \mathrm{g})$.

The study was approved by the Ethical Committee of the 'G Martino' Polyclinic, Messina. Informed consent was obtained from all the women recruited.

\section{Measurements}

Maternal circulating TSH and $\mathrm{FT}_{4}$, TPO-Ab and Tg- $\mathrm{Ab}$ (electrochemiluminescence immunoassay (ECLIA)) were determined using commercial kits supplied by Roche Diagnostics, GmbH. Precision profiles showed inter and intra-assay coefficients of variation $<5 \%$ over the entire measurement range.

\section{Statistical analysis}

Unless otherwise specified data are expressed as mean $\frac{ \pm}{2}$ S.D. Statistical analysis was performed using the $\chi^{\overline{2}}$, or Fisher exact tests when appropriate, for categorical data.

\section{Results}

The clinical and biochemical features at presentation of the 220 studied women are reported in Table 1.

$\mathrm{TPOAb}$ and/or $\mathrm{TgAb}$ were detectable in $18 / 220$ $(8.2 \%)$ women.

\section{Thyroid function abnormalities over gestation}

Raised TSH with or without decreased FT (overt $_{4}$ hypothyroidism $(\mathrm{OH})$ or subclinical hypothyroidism (SCH)) At initial observation, 205/220 (93.2\%) women showed normal TSH values. The remaining $15 / 220(6.8 \%)$ women had raised TSH $(>2.3 \mathrm{mIU} / \mathrm{l})$, and four of them also had serum $\mathrm{FT}_{4}$ below the lowest trimester-specific reference range $(11.9 \mathrm{pmol} / \mathrm{l}$; Fig. 1 , panel $a)$. One third of these women $(5 / 15)$ were antithyroid antibody-positive.

During the second trimester, a further 11 women showed TSH concentrations that were higher than the normal trimester-specific upper limit $(2.8 \mathrm{mIU} / \mathrm{l})$, with abnormally low $\mathrm{FT}_{4}$ concentrations $(<10.4 \mathrm{pmol} / \mathrm{l})$ for gestational age in three of them (Fig. 1, panels b and c). Anti-thyroid antibodies were positive in 3/11 (27.3\%) hypothyroid women. 
Table 1 Characteristics of the studied pregnant women at recruitment $(n=220)$.

\begin{tabular}{|c|c|c|c|c|}
\hline Characteristics & $\begin{array}{c}n \\
\text { (\% of total) }\end{array}$ & Mean \pm s.D. & Median & Range \\
\hline $\begin{array}{l}\text { Maternal age } \\
\text { (years) }\end{array}$ & $220(100)$ & - & 29 & $17-40$ \\
\hline $\begin{array}{l}\text { Gestational age } \\
\text { (weeks) }\end{array}$ & & $10.1 \pm 1.8$ & 10 & $5-12$ \\
\hline$\leq 8$ weeks & 57 (25.9) & $7.1 \pm 1.0$ & 7 & \\
\hline $9-12$ weeks & $163(74.1)$ & $11.0 \pm 1.1$ & 12 & \\
\hline \multicolumn{5}{|l|}{ Parity } \\
\hline 0 & $81(36.8)$ & - & - & - \\
\hline 1 & 74 (33.6) & - & - & - \\
\hline$\geq 2$ & 65 (29.5) & - & - & - \\
\hline $\mathrm{FT}_{4}(\mathrm{pmol} / \mathrm{l})$ & $220(100)$ & $15.7 \pm 2.6$ & 15.7 & $10.3-26.2$ \\
\hline $\mathrm{TSH}(\mathrm{mUl} / \mathrm{l})$ & 220 (100) & $1.06 \pm 0.97$ & 0.85 & $0.01-6.5$ \\
\hline $\begin{array}{l}\text { TPO and/or Tg } \\
\text { Abs positivity }\end{array}$ & $18(8.2)$ & - & & \\
\hline $\begin{array}{l}\text { Urinary iodine } \\
\quad \text { excretion }(\mu \mathrm{g} / \mathrm{l})\end{array}$ & $220(100)$ & - & 96 & $50-385$ \\
\hline
\end{tabular}

Finally, over the third trimester, in none of the women was TSH found to exceed the upper trimester-specific limit (3.0 mIU/l; Fig. 1, panels $d$ and $e$ ).

Overall, overt or SCH affected 26/220 (11.8\%) women, eight of whom (30.7\%) were anti-thyroid antibody-positive.

Isolated low serum $\mathrm{FT}_{4}$ concentrations and normal serum TSH (IH) At initial observation, 7/220 (3.2\%) women had $\mathrm{IH}$, with $\mathrm{FT}_{4}$ concentrations below the lower limit for gestational age but normal TSH levels (Fig. 1, panel a). Of these, only one was anti-thyroid antibody-positive.

A gradual reduction in $\mathrm{FT}_{4}$ concentrations was observed in a high proportion of women over the course of the second trimester; these were found to fall below the lower limit in 28 women, despite TSH concentrations remaining consistently within the normal range (Fig. 1, panels $b$ and c). Anti-thyroid antibodies were positive in 3/28 of these women.

Finally, during the third trimester of gestation, 21 more women, none of whom were TPO and/or Tg Abs positive, displayed subnormal $(<10.3 \mathrm{pmol} / \mathrm{l}) \mathrm{FT}_{4}$ concentrations (Fig. 1, panels $d$ and $e$ ).

Overall, 56/220 (25.4\%) women exhibited IH over the course of gestation and anti-thyroid antibodies were detectable in only $4 / 56(7.1 \%)$ of them.

Overall, 82/220 women (26/82 with $\mathrm{OH} / \mathrm{SCH}$ and $56 / 82$ with $\mathrm{IH}$ ) were given substitutive $\mathrm{L}_{-} \mathrm{T}_{4}$ (median $\mathrm{T}_{4}$ dose $1.65 \mu \mathrm{g} / \mathrm{kg}$ per day). In all of them, serum TSH and/or $\mathrm{FT}_{4}$ values returned to normal within 4 weeks and remained so during further follow up.

\section{Obstetrical and neonatal outcome}

Data relative to obstetrical and neonatal outcomes were obtained for 204/220 women and are shown in Table 2. No differences in either gestational or neonatal
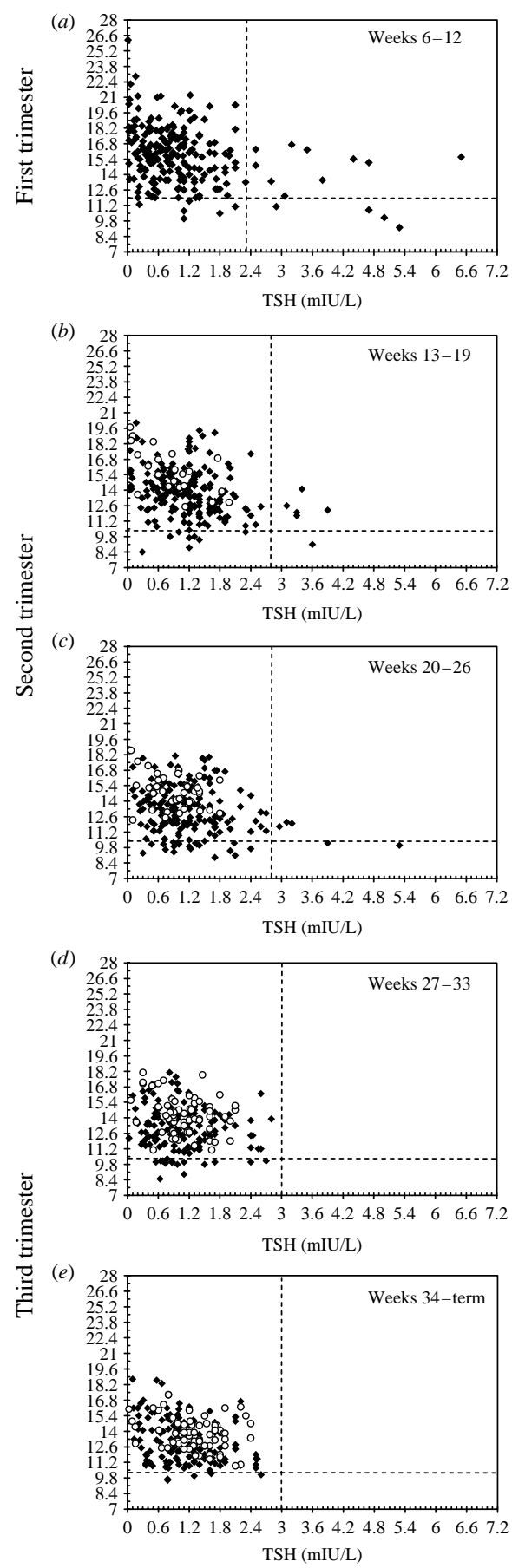

Figure 1 Panels a-e show individual serum $\mathrm{FT}_{4}$ and TSH values at first (week 5-12, panel a), second (week 13-19, panel $b$; week 20-26 panel $c$ ) and third (week 27-33, panel $d$; week 34-pregnancy term, panel e) trimester. The vertical dotted lines indicate the highest normal trimester-specific TSH value $(2.3 ; 2.8$ and $3.0 \mathrm{mlU} / \mathrm{l}$ at first, second and third trimester respectively). The horizontal dotted lines indicate the lowest normal trimester-specific $\mathrm{FT}_{4}$ value $(11.9 ; 10.4$ and $10.3 \mathrm{pmol} / \mathrm{l}$ at first, second and third trimester respectively). Women found to be either hypothyroid or hypothyroxinemic throughout gestation were given substitutive $L-T_{4}$ and are indicated by white symbols $(\mu)$. Untreated women are indicated by black symbols $(\nu)$. 
Table 2 Obstetrical and neonatal outcome $(n=204)$.

\begin{tabular}{|c|c|c|c|c|}
\hline Characteristics & $\mathrm{OH} / \mathrm{SCH}$ on $\mathrm{L}^{-\mathrm{T}_{4}}(n=24)$ & IH on L-T $\mathbf{T}_{4}(n=51)$ & Euthyroid $(n=129)$ & $\boldsymbol{P}$ \\
\hline Preeclampsia \% $(n)$ & $4.2(1)$ & $3.9(2)$ & $3.9(5)$ & NS \\
\hline Gestational week at delivery median (range) & $39(35-42)$ & $39(32-40)$ & $39(32-42)$ & NS \\
\hline Preterm delivery $\%(n)$ & $4.2(1)$ & $3.9(2)$ & $7.7(10)$ & NS \\
\hline Spontaneous delivery $\%(n)$ & $41.7(10)$ & $62.7(32)$ & $68.2(88)$ & NS \\
\hline Caesarean section $\%(n)$ & $58.3(14)$ & $37.3(19)$ & $31.8(41)$ & NS \\
\hline Stillbirths \% $(n)$ & 0 & 0 & $0.7(1)$ & NS \\
\hline Birth weight $(\mathrm{g}) \mathrm{M} \pm$ S.D. (range) & $3237 \pm 504(2000-4400)$ & $3332 \pm 635(2100-4500)$ & $3218 \pm 415(1810-4120)$ & NS \\
\hline Length $(\mathrm{cm}) \mathrm{M} \pm$ S.D. (range) & $49.4 \pm 1.7(46-53)$ & $50.2 \pm 2.7(47-55)$ & $50.1 \pm 1.3(47-52)$ & NS \\
\hline Head circumference $(\mathrm{cm}) \mathrm{M} \pm$ s.D. (range) & $33.9 \pm 1.7(31.5-37)$ & $33.6 \pm 1.2(32-37)$ & $34.5 \pm 0.9(32.5-36)$ & NS \\
\hline 1-min Apgar Score median (range) & $9(5-10)$ & $9(8-9)$ & $9(3-10)$ & NS \\
\hline 5-min Apgar Score median (range) & $10(9-10)$ & $10(9-10)$ & $10(6-10)$ & NS \\
\hline
\end{tabular}

parameters were observed in the women who were found to be consistently euthyroid (129/204) throughout gestation or in those who received substitutive $\mathrm{L}-\mathrm{T}_{4}$ treatment for either $\mathrm{OH} / \mathrm{SCH}(24 / 204)$ or $\mathrm{IH}(51 / 204)$.

\section{Risk of OH/SCH in antibody-positive pregnant women}

Of the $18 / 220$ women who at presentation tested positive for TPO-Abs and/or Tg-Abs, 8/18 (44.4\%) experienced $\mathrm{OH} / \mathrm{SCH}$, during either the first $(5 / 8)$ or the second (3/8) trimester. Of the 202/220 antibodynegative women, $18 / 202(8.9 \%)$ were diagnosed with $\mathrm{OH} / \mathrm{SCH}$. Therefore, the relative risk of $\mathrm{OH} / \mathrm{SCH}$ in antibody-positive women was $5.0 \quad\left(\chi^{2} 20.02\right.$, $P<0.0005$ ).

Of the remaining 10/18 antibody-positive women, $4 / 18(22.2 \%)$ exhibited $\mathrm{IH}$, mostly throughout the second trimester, and 6/18 (33.3\%) displayed no thyroid function abnormalities at any stage of gestation.

\section{Timing of OH/SCH occurrence and potential for misdiagnosing at early thyroid function testing}

The overall prevalence of $\mathrm{OH} / \mathrm{SCH}$ over the course of gestation amounted to $11.8 \%(26 / 220)$. It is interesting to note that of those women experiencing hypothyroidism, just over half of them (15/26) were identified at the presentation. In further follow up, either $\mathrm{OH}$ or $\mathrm{SCH}$ could be detected in the residual $11 / 26$ at both early (6/11, between weeks 13 and 19) and late (5/11, between weeks 20 and 26) phases of the second trimester. Consequently, $42.3 \%$ hypothyroid women would not have been diagnosed, if we had limited our observation to early thyroid function tests alone.

The frequency distribution of $\mathrm{OH} / \mathrm{SCH}$ for each gestational period is shown in Fig. 2 (panel a).

As concerns $\mathrm{IH}$, this mild condition of thyroid underfunction became progressively more common from the end of the first trimester onwards, peaking between weeks 20 and 26 . Indeed, at presentation only seven women displayed $\mathrm{FT}_{4}$ values below the 2.5 percentile for gestational age, the remaining 49/56 (87.5\%) dropped to this limit later in gestation (Fig. 2, panel b).

\section{Discussion}

Our study evaluated the timing of maternal thyroid failure in a cohort of pregnant women from a mildly ID area who had never been tested for thyroid dysfunction prior to becoming pregnant. The main objective of the study was to assess the benefit of thyroid function
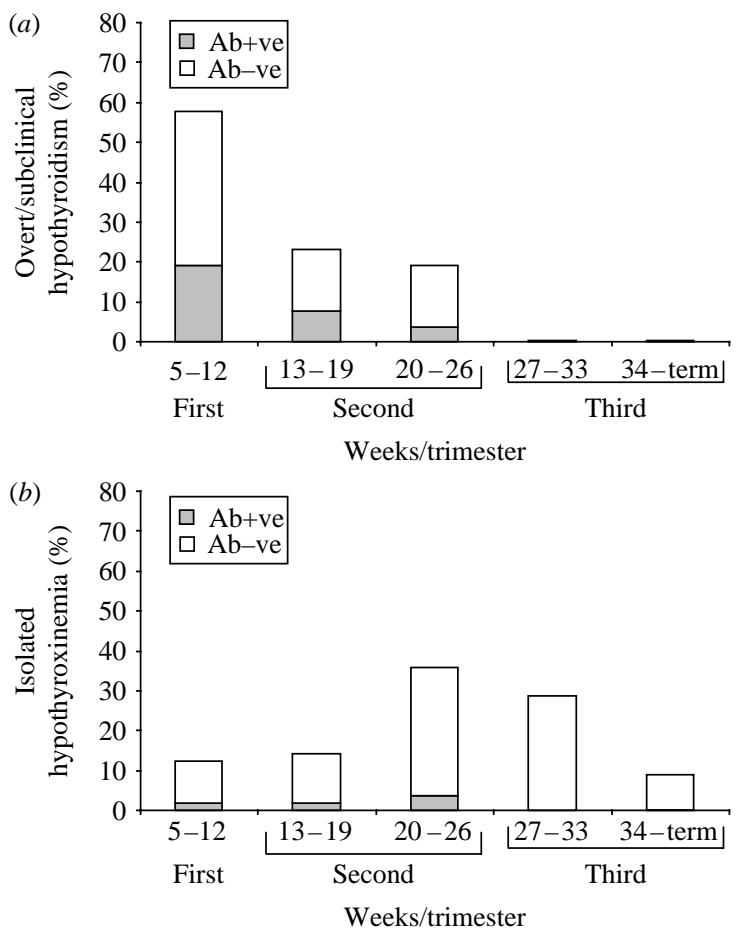

Figure 2 Overall frequency distribution of either hypothyroidism (panel $a$ ) or isolated hypothyroxinemia (panel $b$ ) over the course of gestation. 
testing at early gestation only in identifying maternal thyroid dysfunction.

Very recently, an ad hoc Endocrine Society committee established consensus guidelines that strongly recommend maternal thyroid function screening in selected groups of women considered to be at high risk for thyroid dysfunction, mainly because of a personal or family history of autoimmune disease (13). However, the efficacy of this strategy has recently been called into question, by the results of a prospective study, which concludes that testing only high-risk pregnant women would cause nearly one third of cases of hypothyroidism during early gestation to escape detection $(19,20)$. The recommendations further state that screening should consist of TSH measurement 'performed before pregnancy when possible, or at the first prenatal visit' (13). This timing of intervention would certainly guarantee the prompt identification of women affected with thyroid insufficiency prior to becoming pregnant, but has the potential to overlook any women who might develop thyroid insufficiency in the subsequent stages of pregnancy. Indeed, pregnancy represents a challenge for the maternal thyroid, due to a progressive increase in hormone demand that can only be met by a very marked augmentation in hormone output. This endpoint is ensured by physiological adaptations of the thyroidal economy, provided that the thyroid gland is fully operative and iodine intake adequate (21).

The women included in this study were variously iodine-supplemented. In addition to the regular use of iodised salt, more than one half of them also received multivitamin compounds containing 100-150 $\mu \mathrm{g}$ of iodine. Median UIE at recruitment was consistent with mild iodine deficiency. About $8 \%$ of the women had detectable thyroid auto-antibodies. Overall, the prevalence of either overt or SCH was nearly $12 \%$ and almost $60 \%$ of the hypothyroid women were identified at recruitment. The remaining $40 \%$ became hypothyroid in the further follow up, namely over the course of the second trimester, and would not have been identified, if we had limited our observation to the first thyroid function test alone. Antithyroid autoantibodies were present in about one third of hypothyroid women (more or less equally distributed between the first and second trimesters), and in a small percentage of women who displayed only minor thyroid abnormalities (IH). Overall, thyroid autoimmunity was associated with a fivefold increased risk of hypothyroidism. Nonetheless, the vast majority of women experiencing either overt or $\mathrm{SCH}$ throughout gestation repeatedly tested negative for thyroid antibodies. This suggests that a feature other than thyroid autoimmunity, namely iodine deficiency, might play a major role in the occurrence of hypothyroidism in these women. It is reasonable to believe that the iodine needs of women experiencing thyroid underfunction throughout gestation were not fully met by their daily iodine intake and that the iodine stored in their thyroid gland was not sufficient to ensure adequate hormone synthesis and secretion for the whole gestational period. In other words, the occurrence of maternal thyroid insufficiency during the second trimester in women who proved euthyroid at very early testing might be explained by failure of the maternal thyroid to keep up with increased hormone demand due to an inadequate iodine supply. A similar mechanism might be involved in the occurrence of milder biochemical thyroid abnormalities, such as isolated hypothyroxinaemia, which in our series was observed in nearly one quarter of women, mainly from the end of first trimester onwards, although the cause of isolated hypothyroxinaemia is not fully understood. Epidemiological data from either moderate or mild iodine deficient areas have shown that a critical reduction in maternal $\mathrm{FT}_{4}$, especially during early gestation, may not necessarily be matched by a proportional and simultaneous TSH increase. This is likely due to the fact that, over the first trimester, placental human chorionic gonadotropin stimulates the preferential ID-related thyroidal output of tri-iodothyronine $\left(\mathrm{T}_{3}\right)$, which in turn, triggers negative feedback on pituitary TSH secretion. In these women, therefore, circulating $\mathrm{T}_{3}$ is normal or even slightly over the upper limit, TSH falls within the normal range, and the women are clinically euthyroid even when biochemically hypothyroxinemic (2). The causes of IH in women from iodine-sufficient areas $(19,22)$ are even less clear, though an iodine intake that does not meet the requirements of pregnancy cannot be categorically ruled out in these women either. It remains to be demonstrated whether or not the condition is in fact consistent with potential thyroid failure. It has recently been shown that mild $\mathrm{IH}$ does not affect pregnancy outcome (23). Conversely, present clinical and experimental evidence seems to suggest that early and prolonged (until week 24) maternal hypothyroxinemia is a risk factor for impaired foetal brain development (3, 22, 24-26). Moreover, other reports of poor developmental outcome in preterm babies indicate that a normal supply of maternal $\mathrm{T}_{4}$ continues to have an important protective role after midgestation $(27,28)$. Because of the potential irreversibility of foetal brain damage, we decided arbitrarily to give substitutive $\mathrm{L}-\mathrm{T}_{4}$ treatment to women experiencing $\mathrm{IH}$, in order to ensure $\mathrm{FT}_{4}$ levels similar to those observed in adequately iodine supplemented women at the same stage of pregnancy. We do not know whether or not this strategy of intervention improved obstetrical and neonatal outcomes, due to the lack of a control group of untreated hypothyroid/hypothyroxinemic women. Actually, no differences were observed in the pregnancy outcomes of either $\mathrm{L}_{-} \mathrm{T}_{4}$ treated or persistently euthyroid pregnant women or in their newborns. Nonetheless, this aspect was beyond the scope of our study, whose principal focus was on the timing of the occurrence of maternal thyroid underfunction. Accordingly, the main conclusion of our study is that in mildly ID areas thyroid 
function testing early in gestation is only partly effective in identifying thyroid dysfunction in pregnant women, because maternal thyroid underfunction also occurs later in gestation in apparently healthy women and in the absence of thyroid autoimmunity. Of course, a strategy of systematic screening and monitoring of thyroid function in all pregnant women from mildly ID areas should first be justified by cost-benefit analyses specifically designed to clarify this issue. Nonetheless, since iodine deficiency is the main cause of maternal thyroid insufficiency all over the world $(29,30)$, basic prevention should consist of adequate and long-term iodine supplementation of women of child-bearing age prior to becoming pregnant, in order to permit the accumulation of sufficient iodine stores to meet the increased needs of both mother and foetus.

\section{Declaration of interest}

The authors have nothing to disclose.

\section{Funding}

This research did not receive any specific grant from any funding agency in the public, commercial or not-for-profit sector.

\section{References}

1 Poppe K \& Glinoer D. Thyroid autoimmunity and hypothyroidism before and during pregnancy. Human Reproduction Update 20039 149-161.

2 Morreale de Escobar G, Obregon MJ \& Escobar del Rey F. Role of thyroid hormone during early brain development. European Journal of Endocrinology 2004151 U25-37.

3 Vermiglio F, Lo Presti VP, Moleti M, Sidoti M, Tortorella G, Scaffidi G, Castagna MG, Mattina F, Violi MA, Crisà A, Artemisia A \& Trimarchi F. Attention deficit and hyperactivity disorders in the offspring of mothers exposed to mild-moderate iodine deficiency: a possible novel iodine deficiency disorder in developed countries. Journal of Clinical Endocrinology and Metabolism $2004896054-6060$.

4 Pop VJ, Kuijpens JL, van Baar AL, Verkerk G, van Son MM, de Vijlder JJ, Vulsma T, Wiersinga WM, Drexhage HA \& Vader HL. Low maternal free thyroxine concentrations during early pregnancy are associated with impaired psychomotor development in infancy. Clinical Endocrinology 199950 149-155.

5 Kooistra L, Crawford S, van Baar AL, Brouwers EP \& Pop VJ. Neonatal effects of maternal hypothyroxinemia during early pregnancy. Pediatrics 2006117 161-167.

6 Wartofsky L, Van Nostrand D \& Burkman KD. Overt and 'subclinical' hypothyroidism in women. Obstetrical and Gynecological Survey $2006 \mathbf{6 1}$ 535-542.

7 Lazarus JH \& Premawardhana LD. Screening for thyroid disease in pregnancy. Journal of Clinical Pathology 2005 58 449-452.

8 Allan WC, Haddow JE, Palomaki GE, Williams JR, Mitchell ML, Hermos RJ, Faix JD \& Klein RZ. Maternal thyroid deficiency and pregnancy complications: implications for population screening. Journal of Medical Screening 20007 127-130.

9 Casey BM \& Leveno KJ. Thyroid disease in pregnancy. Obstetrics and Gynecology $2006 \mathbf{1 0 8} 1283-1292$.

10 Surks MI, Ortiz E, Daniels GH, Sawin CT, Col NF, Cobin RH, Franklyn JA, Hershman JM, Burman KD, Denke MA, Gorman C,
Cooper RS \& Weissman NJ. Subclinical thyroid disease: scientific review and guidelines for diagnosis and management. Journal of the American Medical Association $2004291228-238$.

11 Hollowell JG, LaFranchi S, Smallridge RC, Spong CY, Haddow JE \& Boyle CA. Where do we go from here? Summary of working group discussions on thyroid function and gestational outcomes Thyroid $20051572-76$.

12 American Thyroid Association. Consensus Statement \#2: American Thyroid Association statement on early maternal thyroidal insufficiency: recognition, clinical management and research directions. Thyroid 200515 77-79.

13 Abalovich M, Amino N, Barbour LA, Cobi RH, De Groot LJ, Glinoer D, Mandel SJ \& Stagnaro-Green A. Management of thyroid dysfunction during pregnancy and postpartum: an endocrine society clinical practice guideline. Journal of Clinical Endocrinology and Metabolism 200792 S1-47.

14 Trimarchi F, Vermiglio F, Finocchiaro MD, Battiato S, Lo Presti VP, La Torre N, Calaciura F, Regalbuto C, Sava L \& Vigneri R. Epidemiology and clinical characteristics of endemic cretinism in Sicily. Journal of Endocrinological Investigation 1990 13 543-548.

15 Vermiglio F, Lo Presti VP, Scaffidi Argentina G, Finocchiaro MD, Gullo D, Squatrito S \& Trimarchi F. Maternal hypothyroxinemia during the first half of gestation in an iodine deficient area with endemic cretinism and related disorders. Clinical Endocrinology 199542 409-415.

16 Vermiglio F, Sidoti M, Finocchiaro MD, Battiato S, Lo Presti VP, Benvenga $S$ \& Trimarchi F. Defective neuromotor and cognitive ability in iodine-deficient schoolchildren of an endemic goiter region in Sicily. Journal of Clinical Endocrinology and Metabolism 199070 379-384.

17 Vermiglio F, Lo Presti VP, Castagna MG, Violi MA, Moleti M, Finocchiaro MD, Mattina F, Artemisia A \& Trimarchi F. Increased risk of maternal thyroid failure with pregnancy progression in an iodine deficient area with major iodine deficiency disorders. Thyroid 19999 19-24.

18 Moleti M, Lo Presti VP, Campolo MC, Mattina F, Galletti M, Mandolfino M, Violi MA, Giorgianni G, De Domenico D, Trimarchi F \& Vermiglio F. Iodine prophylaxis using iodized salt and risk of maternal thyroid failure in conditions of mild iodine deficiency. Journal of Clinical Endocrinology and Metabolism 2008 $932616-2621$.

19 Vaidya B, Anthony S, Bilous M, Shields V, Drury J, Hutchison S \& Bilous R. Detection of thyroid dysfunction in early pregnancy: universal screening or targeted high-risk case finding? Journal of Clinical Endocrinology and Metabolism $2007 \mathbf{9 2}$ 203-207.

20 Brent G. Editorial: diagnosing thyroid dysfunction in pregnant women: is case finding enough? Journal of Clinical Endocrinology and Metabolism 200792 39-41.

21 Glinoer D. The regulation of thyroid function in pregnancy: pathways of endocrine adaptation from physiology to pathology. Endocrine Reviews 199718 404-433.

22 Pop VJ, Brouwers EP, Vader HL, Vulsma T, van Baar AL \& de Vijlder JJ. Maternal hypothyroxinemia during early pregnancy and subsequent child development: a 3-year follow up study. Clinical Endocrinology $200359282-288$.

23 Casey BM, Dashe JS, Spong CY, McIntire DD, Leveno KJ \& Cunningham GF. Perinatal significance of isolated maternal hypothyroxinemia identified in the first half of pregnancy. Obstetrics and Gynecology 2007109 1129-1135.

24 Morreale de Escobar G, Obregon MJ \& Escobar del Rey F. Is neuropsychological development related to maternal hypothyroidism or to maternal hypothyroxinemia? Journal of Clinical Endocrinology and Metabolism 200085 3975-3987.

25 Lavado-Autric R, Auso E, Garcia-Velasco JV, Arufe Mdel C, Escobar del Rey F, Berbel P \& Morreale de Escobar G. Early maternal hypothyroxinemia alters histogenesis and cerebral cortex cytoarchitecture of the progeny. Journal of Clinical Investigation 20037 1073-1082. 
26 Auso E, Lavado-Autric R, Cuevas E, Del Rey FE, Morreale De Escobar G \& Berbel P. A moderate and transient deficiency of maternal thyroid function at the beginning of fetal neocorticogenesis alters neuronal migration. Endocrinology 20049 4037-4047.

27 den Ouden AL, Kok JH, Verkerk PH, Brand R \& VerlooveVanhorick SP. The relation between neonatal thyroxine levels and neurodevelopmental outcome at 5 and 9 years in a national cohort of very preterm and/or very low birth weight infants. Pediatric Research 199639 143-145.

28 Reuss ML, Paneth N, Pinto-Martin JA, Lorenz JM \& Susser M. The relation of transient hypothyroxinemia in preterm infants to neurologic development at two years of age. New England Journal of Medicine $1996334821-827$.
29 de Escobar GM, Obregòn MJ \& del Rey FE. Iodine deficiency and brain development in the first half of pregnancy. Public Health Nutrition 200710 1554-1570.

30 Andersson M, de Benoist B, Delange F \& Zupan J, WHO Secretariat on behalf of the participants to the Consultation. Prevention and control of iodine deficiency in pregnant and lactating women and in children less than 2-years-old: conclusions and recommendations of the Technical Consultation. Public Health Nutrition $20071021606-1611$.

Received 15 January 2009

Accepted 26 January 2009 